\title{
Receptor GPS em Software
}

\author{
Fabrício de Araújo Carvalho, Alexandre Boa Ventura Oliveira, F. Walter
}

\begin{abstract}
Resumo - O atual estágio de desenvolvimento do receptor GPS em Software é apresentado, destacando as características do sinal GPS e as etapas de processamento em software: correlator e a interface com o usuário. $O$ uso do receptor para o estudo dos erros devido à atmosfera também é mostrado.
\end{abstract}

Palavras-chave - GPS, Correlator, Receptor por Software, DSP, correlação, PRN.

Abstract - The current development of GPS software receiver is presented, detaching the characteristics of the GPS signal and the stages of processing in software: correlator and the interface with the user. The use of the receiver to study errors due to the atmosphere also is shown.

Keywords - GPS, Correlator, Software Receiver, DSP, correlation, PRN.

\section{INTRODUÇÃO}

O desenvolvimento de um receptor GPS em "software" para o sinal L1 é descrito. Para o teste do seu funcionamento foram gerados os dados transmitidos pelos satélites GPS incluindo os efeitos do canal entre o transmissor (satélite) e o usuário (receptor), tais como: o atraso produzido pela atmosfera (ionosfera mais a troposfera) e o efeito Doppler. O receptor consiste basicamente de um correlator e de uma interface com o usuário mostrando sua posição.

\section{SINAL GPS}

Os sinais transmitidos pelos satélites GPS transportam as informações necessárias para que receptores possam determinar a sua localização. A informação é uma seqüência de dados binários representados na expressão:

$$
D_{i}(t)=\sum_{k} d_{i k} \prod\left[\frac{t-k T_{b}}{T_{b}}\right]
$$

onde: $D_{i}(t)$ é o trem de pulso para o $\mathrm{i}^{\text {-ésimo }}$ satélite; $\mathrm{d}_{\mathrm{ik}}$ é o valor do bit $\mathrm{k}$; e $\mathrm{T}_{\mathrm{b}}$ o período do pulso retangular $(50 \mathrm{~Hz})$ representado por $\Pi[$ [.]

Os bits de dados modulam um código pseudo-aleatório (PRN), o qual é responsável pelo espalhamento espectral do sinal.

As portadoras, L1 e L2, transmitidas pelos satélites estão na banda 1 a $2 \mathrm{GHz}$ e são moduladas por seqüências PRN distintas.

Fabrício de Araújo Carvalho, Alexandre Boa Ventura Oliveira e F. Walter, Laboratório GNSS, Divisão de Engenharia Eletrônica, ITA Instituto Tecnológico de Aeronáutica, São José dos Campos, SP, Brasil. E-mails: fabrício@ita.br; alexbvo@ita.br; fw2@ita.br. Este trabalho é financiado pela FINEP (Convênio 1825/04, Contrato 01.05.0154.00).
Estas portadoras utilizam a mesma freqüência de referência $(10,23 \mathrm{MHz})$ que ao ser multiplicada por um fator de 154 , para L1, e 120, para L2, gera as freqüências de $1.575,42 \mathrm{MHz}$ e $1.227,6 \mathrm{MHz}$, respectivamente. A freqüência de referência é também empregada para obter a taxa do código PRN e dos dados de navegação.

$\mathrm{O}$ código PRN utilizado pela componente em fase do sinal L1 (sinal de interesse) é denominado por código C/A (Coarser Acquisition) e apresenta uma taxa de 1,023 MHz. $\mathrm{O}$ código $\mathrm{C} / \mathrm{A}$ pertence à família de códigos de Gold, podendo ser representado por:

$$
C_{i}(t)=\sum_{n=0}^{N-1} c_{i n} \prod\left[\frac{t-n T_{\text {chip }}}{T_{\text {chip }}}\right]
$$

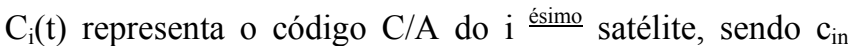
igual 1 ou 0 , com duração $\mathrm{T}_{\text {chip }}(1 / 1,023 \mathrm{MHz})$ e $\mathrm{N}$ o comprimento do código (1023 “chips").

O termo "chip" é usado amplamente na área de navegação global por satélites (GPS, GLONASS e Galileo) para distinguir o bit de código do de informação (usado para os dados de navegação).

$\mathrm{O}$ sinal $\mathrm{C}_{\mathrm{i}}(\mathrm{t})$ é periódico (3) e se repete a cada intervalo de duração $T_{p}$, que corresponde a $T_{\text {chip }} \times \mathrm{N}$.

$$
C_{i}(t)=\sum_{k=0}^{\infty} \sum_{n=0}^{N-1} c_{i n} \prod\left[\frac{t-n T_{\text {chip }}-k T_{p}}{T_{\text {chip }}}\right]
$$

\begin{tabular}{|c|c|}
\hline \multicolumn{2}{|c|}{ Tabela I: Polinômios geradores de código PRN } \\
\hline Reg. & Polinômio \\
\hline G1 $(\mathrm{t})$ & $1 \oplus x^{3} \oplus x^{10}$ \\
\hline G2(t) & $1 \oplus x^{2} \oplus x^{3} \oplus x^{6} \oplus x^{8} \oplus x^{9} \oplus x^{10}$ \\
\hline
\end{tabular}

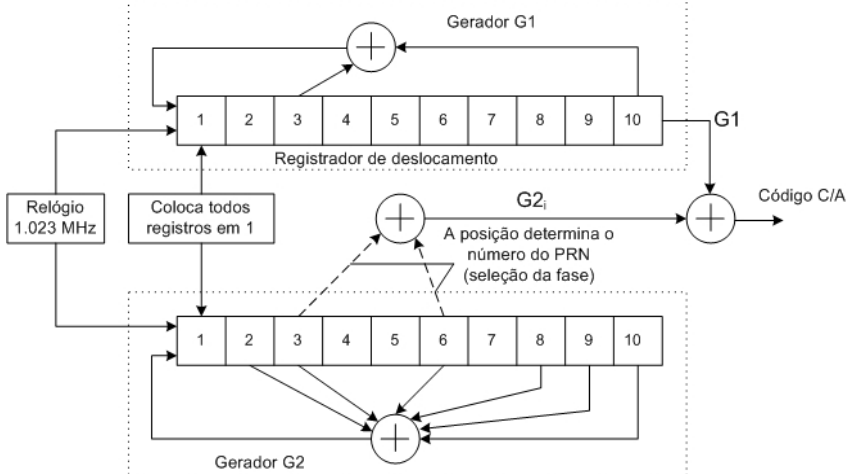

Fig. 1 Gerador do código C/A. A seleção de fase é definida pelo par de células utilizadas como saída no gerador G2(t).

$\mathrm{O}$ código $\mathrm{C} / \mathrm{A}$ é gerado através de dois geradores de deslocamento linear, contendo, cada um, dez células. O 
número "n" de células determina o comprimento do código, resultando, para $\mathrm{n}=10$, em um período de $1 \mathrm{~ms}\left(\mathrm{~N}=2^{\mathrm{n}}-1=\right.$ 1023). Estes geradores são descritos através dos polinômios: G1(t) e G2(t) mostrados na Tabela I.

O polinômio indica a operação soma módulo- $2, \oplus$, entre as células do registrador, identificadas através de seu expoente. $\mathrm{O}$ algoritmo gerador do código $\mathrm{C} / \mathrm{A}$ é ilustrado na Figura 1 [1]. São gerados no sistema GPS 36 códigos C/As através da operação soma módulo-2 e de uma adequada realimentação e seleção de fase.

$\mathrm{O}$ espectro para o código $\mathrm{C} / \mathrm{A}$ pode ser observado no gráfico da Figura 2.

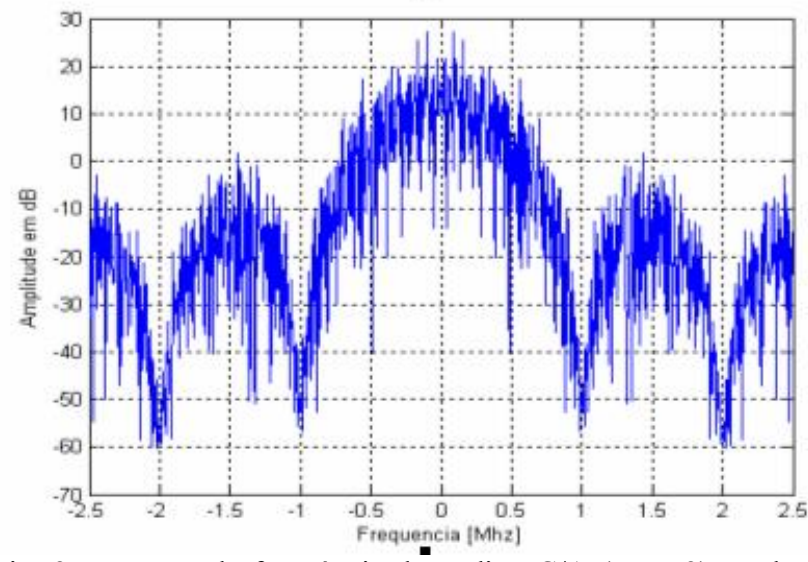

Fig. 2. Espectro de freqüência do código C/A (PRN 2) em banda base. Largura de faixa de 2,046 MHz.

$\mathrm{O}$ código $\mathrm{C} / \mathrm{A}$ foi adotado devido às suas características de autocorrelação e correlação cruzada (Figuras 3 e 4).

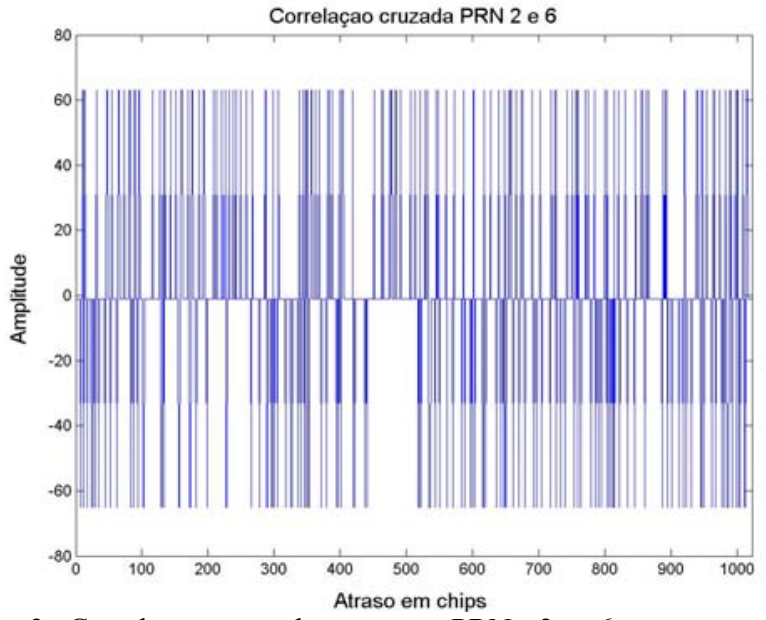

Fig. 3. Correlação cruzada entre os PRNs 2 e 6, com passo de código inteiro.

A correlação para códigos distintos apresenta baixos valores de amplitude: $-65,-1$ e 63 .

No caso da autocorrelação, o valor de amplitude chega a 1023 (para códigos alinhados), mas os valores para atrasos do código superiores a um chip são semelhantes ao da correlação cruzada.

A grande diferença entre o pico de máxima correlação e os picos de correlação cruzada corresponde ao ganho de processamento obtido durante os processos de aquisição e o de rastreamento.

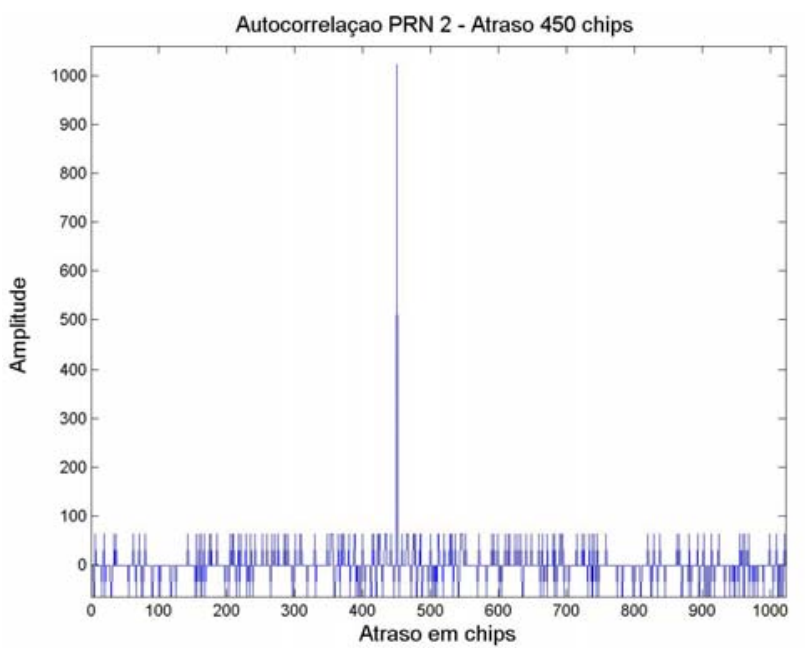

Fig. 4. Autocorrelação para o PRN 2, com atraso de 450 chips evidenciando o pico de correlação.

O sinal transmitido, mostrado na Figura 5, é um sinal BPSK e pode ser representado pela eq. (4):

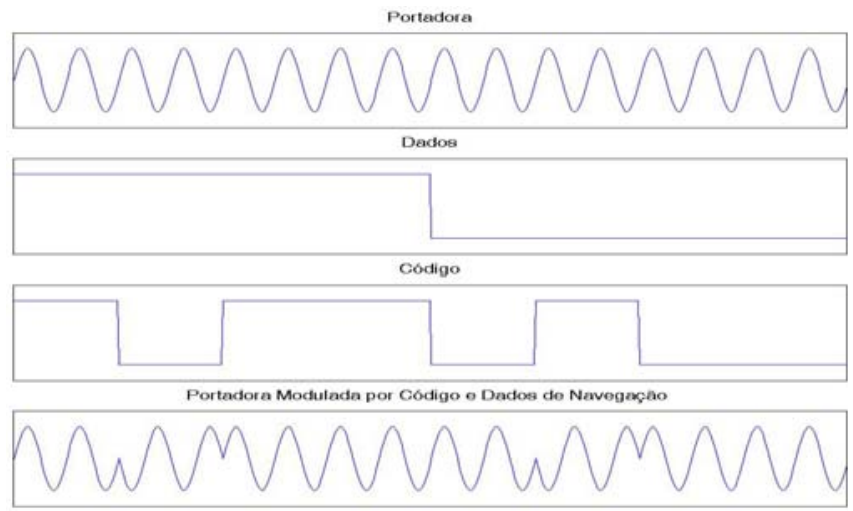

Fig. 5. Ilustração do sinal GPS. De cima para baixo: portadora, dados, código PRN e sinal L1 em fase.

$$
\begin{aligned}
& L 1_{i}(t)= \\
& \underbrace{\sqrt{2 P_{c}} C_{i}[t-\tau(t)] \cdot D_{i}[t-\tau(t)] \cos \left(2 \pi\left(f_{L 1}+f_{D i}\right) t+\theta_{i}\right)}_{\begin{array}{c}
\text { Sinal de int eresse } \\
S_{i}(t)
\end{array}}
\end{aligned}
$$

onde: $\mathrm{L} 1_{\mathrm{i}}$ é o sinal recebido; $\tau(\mathrm{t})$ o atraso do sinal, $\mathrm{P}_{\mathrm{c}}$ a potência recebida; $\mathrm{C}_{\mathrm{i}}(\mathrm{t})$ o código $\mathrm{C} / \mathrm{A} ; \mathrm{D}_{\mathrm{i}}(\mathrm{t})$ os dados de navegação; $f_{L 1}$ a freqüência da portadora L1; e $f_{D i}$ a freqüência Doppler [2].

O sinal GPS é simulado para uma avaliação do correlator, [3] sendo composto pelos sinais de um número variável de satélites, cada sinal, caracterizado por um único código C/A e um dado valor de Doppler e atraso, bem como dados de navegação que indicam sua posição.

O Doppler na freqüência de portadora se deve ao movimento relativo entre satélite e receptor e varia de $\pm 5 \mathrm{kHz}$ em relação à freqüência central, podendo chegar a $\pm 10 \mathrm{kHz}$ para usuários com alta dinâmica.

\section{SINAL RECEBIDO}

Ao ser recebido pela antena do receptor, o sinal GPS apresenta uma potência da ordem de $10^{-16}$ watts $(-160 \mathrm{dBw})$, bem abaixo do ruído térmico presente no meio (cerca de $141 \mathrm{dBw})$. Este valor de ruído é calculado em função da 
largura de faixa, B, do sinal de interesse $(2,046 \mathrm{MHz}$ do código do $\mathrm{C} / \mathrm{A}$ ), através da expressão: $\mathrm{N}_{\mathrm{ent}}=\mathrm{kTB}$, onde $\mathrm{k}$ corresponde à constante de Boltzmann $\left(1.38 \times 10^{-23} \mathrm{~J} / \mathrm{K}\right)$ e $\mathrm{T}$ à temperatura dada em Kelvin.

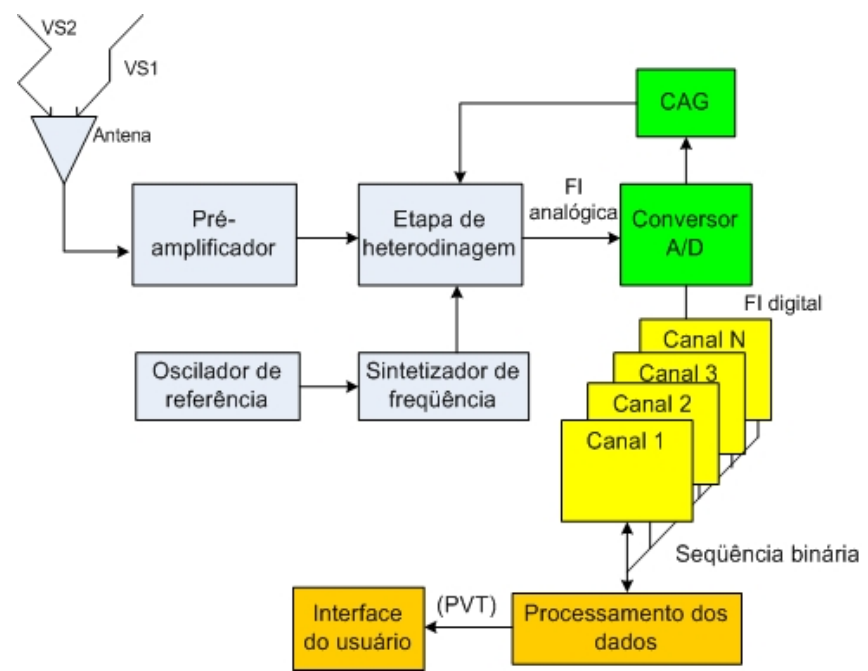

Fig. 6. Diagrama em blocos de um receptor GPS típico. Os blocos em azul correspondem à etapa de heterodinagem, seguida pelo conversor A/D sinalizado em verde. A etapa de correlação em amarelo ilustra os $\mathrm{N}$ canais operando paralelamente, seguido pelo processamento da mensagem de navegação, em laranja.

O processo de condicionamento do sinal é normalmente implementado em duas ou três etapas de heterodinagem, durante as quais o sinal GPS sofre sucessivas amplificações obtendo um ganho final aproximado de $100 \mathrm{~dB}$ e uma FI aproximadamente 1000 vezes inferior que a RF recebida. Tal processo pode ser abstraído através da análise espectral do sinal (Figura 7):

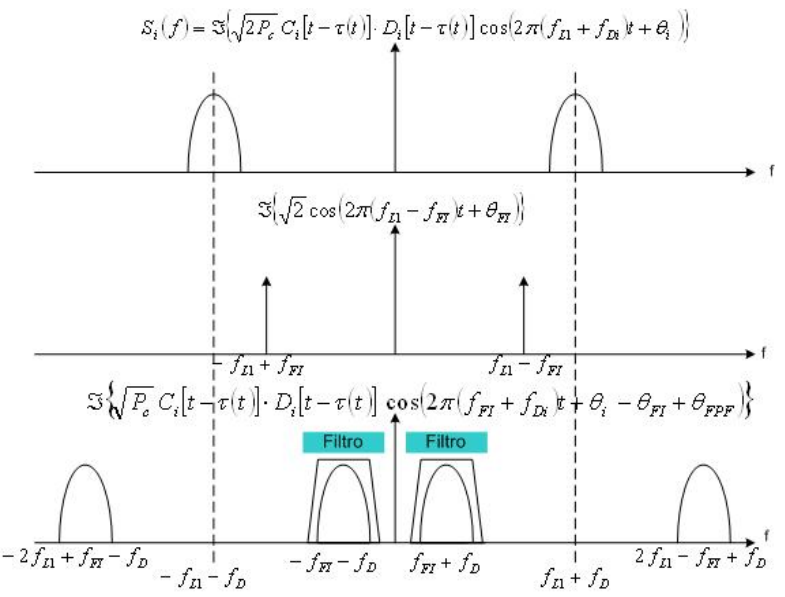

Fig. 7. Analise espectral da heterodinagem e escolha da FI inferior através de um filtro passa faixa.

Após o condicionamento do sinal, a última FI (analógica) deve ser então digitalizada para que o restante do processamento possa ser feito através de software.

A Figura 8 ilustra a digitalização da FI analógica através da subamostragem. A FI analógica adotada foi de $21,25 \mathrm{MHz}$ e o conversor A/D de 5 Msps com palavra de 16 bits. Alguns cuidados são levados em consideração para que os processos, de aquisição e de rastreamento não sejam prejudicados pela digitalização.

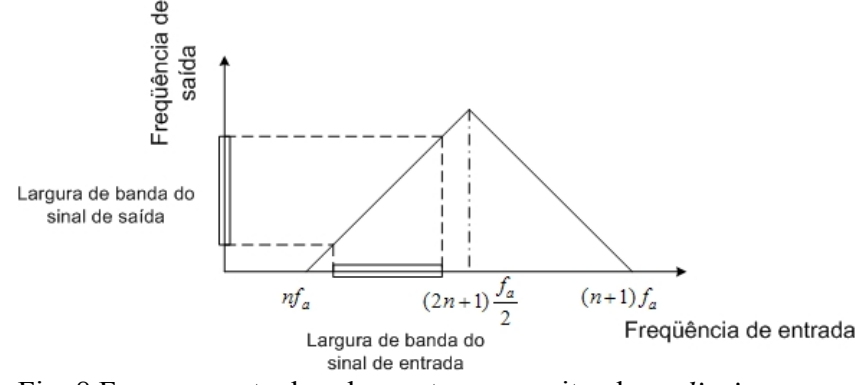

Fig. 8 Forma correta da subamostragem, evitando o aliasing.

O primeiro deles é respeitar o critério de Nyquist e certificar que a taxa de amostragem não seja um múltiplo da taxa do código C/A. É importante também adotar o mesmo referencial de tempo para o downconverter e para o conversor A/D. Caso o conversor seja de 1 bit é necessário o uso do CAG (controlador de ganho automático).

\section{Processamento do SinAL}

A primeira etapa de processamento por software ocorre no correlator implementado em um DSP, o TMS 320C6711. Nele o processamento é dividido em etapas, denominadas por: Aquisição, Confirmação, Alinhamento e Rastreamento, cada qual com uma função específica [4].

A Aquisição tem como função estabelecer um alinhamento grosseiro entre o sinal BPSK gerado internamente (no correlator) com a FI digitalizada. Para tal, o correlator consulta o almanaque (dados das efemérides de todos os satélites, enviados junto com as mensagens de navegação) os prováveis PRNs visíveis (satélites) e os aloca nos canais disponíveis. Alocados os PRNs tem início à busca bidimensional para identificar o atraso do código e a freqüência de portadora (Figura 9).

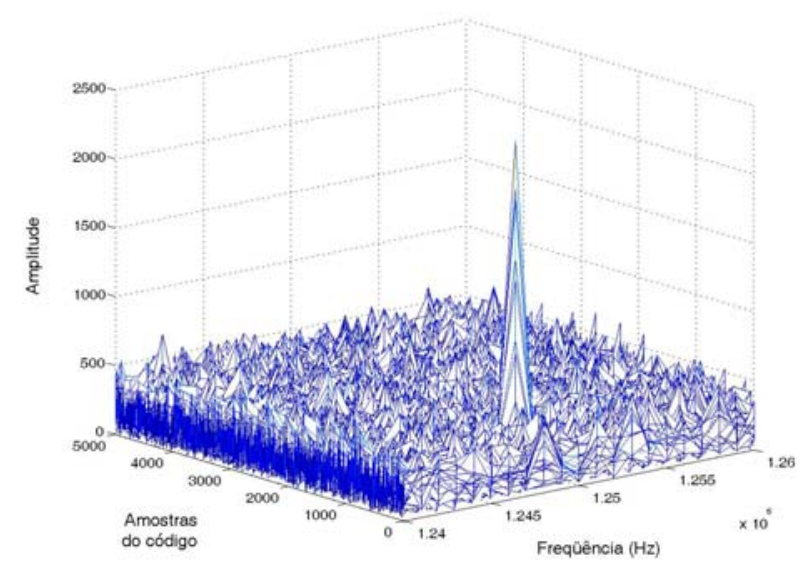

Fig. 9. Resultado do processo de correlação. Busca bidimensional. Atraso de 1000 amostras e Doppler de 1kHz.

No final da aquisição, os dados de atraso e do Doppler, são transferidos para a etapa de Confirmação.

A etapa de Confirmação reduz a probabilidade de falso alarme gerado pelo ruído através do uso do algoritmo de detecção Tong [5]. Durante esta etapa são realizadas as correlações entre o sinal recebido com o sinal interno gerado com os parâmetros, fornecidos pela etapa anterior. Este processo de confirmação é repetido até que o número de 
confirmações ultrapasse um valor pré-determinado, sendo então o sinal considerado presente, seguindo o processamento para a etapa seguinte, de Alinhamento.

O Alinhamento inicialmente utiliza como parâmetros aqueles obtidos na etapa de aquisição e tem como função promover o ajuste fino do sinal gerado internamente, tanto no código como na freqüência. Primeiramente é feito um alinhamento mediano da freqüência e do código para só então se aplicar o alinhamento fino. Após este ajuste, é executado o algoritmo de sincronismo de bit, cuja função é identificar o instante de inversão do código causado pelos dados de navegação. $\mathrm{O}$ conhecimento do instante de inversão do bit permite a integração durante todo o intervalo de $20 \mathrm{~ms}$.

O Rastreamento (Figura 10) extrai os dados de navegação contidos no sinal e mantém o alinhamento do código e da FI com o sinal recebido. Para isso, a etapa apresenta um laço de rastreamento para o código e outro para a portadora. Após o período de integração os valores de amplitude de correlação são passados para os discriminadores de código e portadora para que os ajustes necessários possam ser feitos.

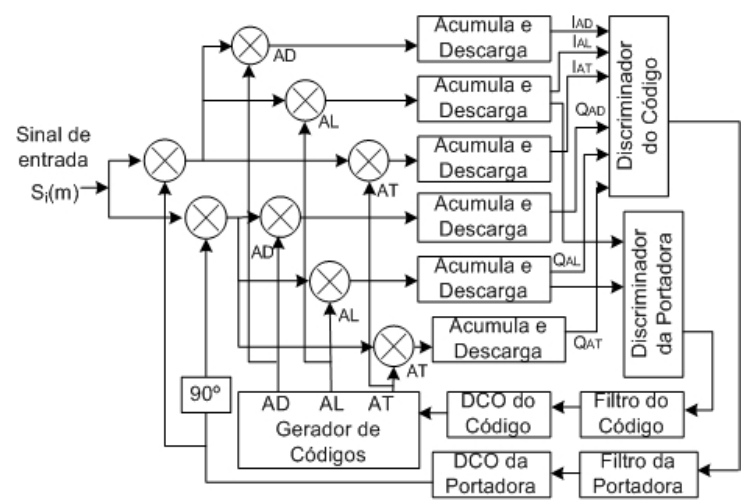

Fig. 10. Etapa de Rastreamento mostrando as correlações em fase e quadratura para os sinais adiantado, alinhado e atrasado em fase e quadratura.

O discriminador de código emprega os valores de correlação obtidos para versões do código adiantadas e atrasadas de meio chip em relação ao sinal gerado internamente. Através das amplitudes destas correlações é possível determinar a correção necessária.

O discriminador de portadora utiliza os valores de correlação em fase $\left(R_{I}\right)$ e quadratura $\left(R_{Q}\right)$ do sinal alinhado em períodos consecutivos para determinar o ajuste da freqüência e da fase, utilizando a função $\operatorname{atan}\left(\mathrm{R}_{\mathrm{Q}}, \mathrm{R}_{\mathrm{I}}\right)$. Os filtros presentes nos laços têm como função eliminar, além do ruído, as componentes de freqüências indesejadas.
Os dados de navegação (Figura 11) são extraídos enquanto as correções no alinhamento do código e da freqüência estão sendo realizadas. Os bits de dados são recuperados utilizando um algoritmo de detecção de inversão. A cada $20 \mathrm{~ms}$ de sinal recebido é feita a verificação da diferença de ângulo entre amostras consecutivas de código. Caso essa diferença seja maior que $90^{\circ}$ ocorre a inversão dos bits de dados.

\section{V - Mensagem de NAVEGaÇão}

No sistema GPS cada satélite envia uma mensagem de navegação composta de 5 sub-quadros sendo que os subquadros 1, 2 e 3 transmitem os dados de efemérides utilizados para o cálculo da posição do satélite em órbita e os sub-quadros 4 e 5 transmitem informações do almanaque com dados de efemérides de todos satélites, modelos troposféricos e ionosféricos (modelo Klobuchar), saúde (confiável ou não os dados), entre outros.

Subquadros $12 \mathrm{e} 3$
Subquadro 1
1000101100000010011010001100000100010101001100
1010011110110000100110100100010000001000001001
0111000011110101101001110011100110001010001011
0010010111010011011101100001010101111011011011
111110100111111011101001011011111011110010100
1010111100000000000000000000010000101100000000
110110000100011011000111
Subquadro 2
1000101100000010011010001100001001111111000111
1010100100100011011111000001010000100010101100
1110100011100111101101010111010011110100100010
1001011111100000010000011010000000010101111111
0110111111001101011001000000010010101010101010
0001111110000011010011011010101010011000011110
010100101001110101101111
Subquadro 3
1000101100000010011010001100001001111111001000
0010110010010000000000000111001010110001100101
1111110001111000000010001000000000000100001000
1001100010110001110100001000000111011010100001
1000001011000001011010101010101111111010000100
111001010111111111010001111001111111011110111
110001100000001110001100

Fig. 11. Sub-quadros 1,2 e 3 transmitidos por um satélite da constelação GPS. Os sub-quadros 1, 2 e 3 fornecem os dados de efemérides utilizados para o cálculo da posição dos satélites.

\begin{tabular}{|c|c|c|c|c|c|c|c|c|c|c|c|c|c|c|c|c|c|c|c|c|c|c|c|c|c|c|c|c|c|}
\hline \multicolumn{30}{|c|}{ PALAVRA (1) TLM } \\
\hline $\begin{array}{l}1 \\
1\end{array}$ & $\begin{array}{l}2 \\
\mathbf{0}\end{array}$ & $\begin{array}{l}3 \\
\mathbf{0}\end{array}$ & $\begin{array}{l}4 \\
0\end{array}$ & $\begin{array}{l}5 \\
1\end{array}$ & $\begin{array}{l}6 \\
\mathbf{0}\end{array}$ & $\begin{array}{l}7 \\
1\end{array}$ & $\begin{array}{l}8 \\
1\end{array}$ & 9 & $\begin{array}{l}1 \\
0\end{array}$ & $\begin{array}{l}1 \\
1\end{array}$ & $\begin{array}{l}1 \\
2\end{array}$ & $\begin{array}{l}1 \\
3\end{array}$ & $\begin{array}{l}1 \\
4\end{array}$ & $\begin{array}{l}1 \\
5\end{array}$ & $\begin{array}{l}1 \\
6\end{array}$ & $\begin{array}{l}1 \\
7\end{array}$ & $\begin{array}{l}1 \\
8\end{array}$ & $\begin{array}{l}1 \\
9\end{array}$ & $\begin{array}{l}2 \\
0\end{array}$ & $\begin{array}{l}2 \\
1\end{array}$ & $\begin{array}{l}2 \\
2\end{array}$ & $\begin{array}{l}2 \\
3\end{array}$ & \begin{tabular}{|l|}
2 \\
4
\end{tabular} & $\begin{array}{l}2 \\
5\end{array}$ & $\begin{array}{l}2 \\
6\end{array}$ & $\begin{array}{l}2 \\
7\end{array}$ & $\begin{array}{l}2 \\
8\end{array}$ & $\begin{array}{l}2 \\
9\end{array}$ & $\begin{array}{l}3 \\
0\end{array}$ \\
\hline \multicolumn{8}{|c|}{ PRE-AMBULO } & \multicolumn{16}{|c|}{ RESERVADA } & \multicolumn{6}{|c|}{ PARIDADE } \\
\hline
\end{tabular}

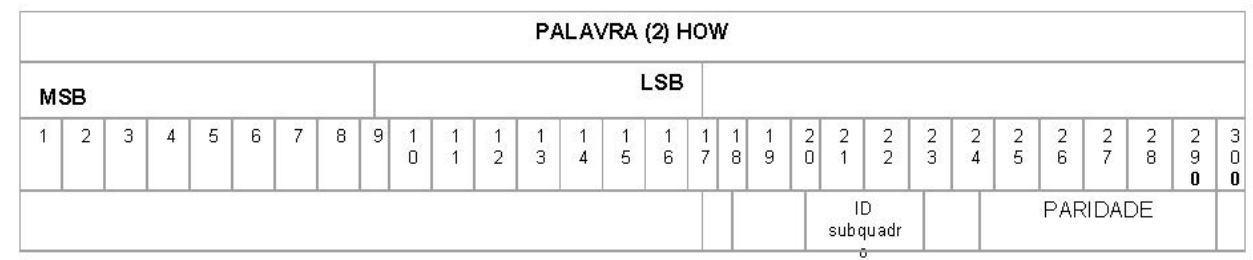

Fig. 12. Palavras 1 e 2 dos sub-quadros na mensagem de navegação 


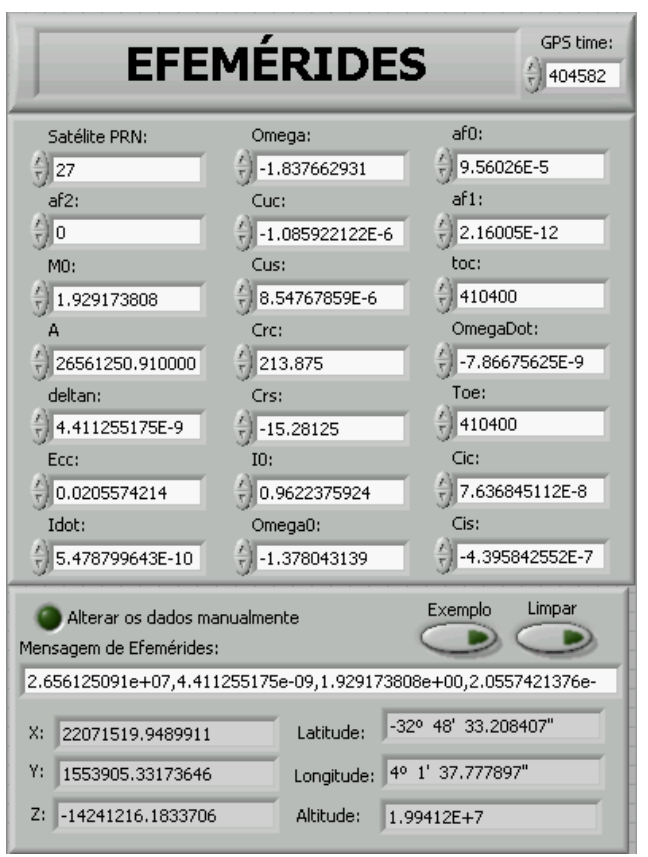

Fig. 13. Dados de efemérides (Segundos da semana GPS: 404582) extraídos dos sub-quadros 1,2 e 3 da Figura 11. A posição do satélite calculada é mostrada como X, Y e Z, bem como as coordenadas geográficas correspondente ao datum WGS-84, Latitude, Longitude e Altitude.

Cada sub-quadro é composto por 10 palavras e cada palavra possui 30 bits. A Figura 12 mostra as palavras 1 e 2, usadas para identificar o sub-quadro.

Cada sub-quadro começa com um cabeçalho (preâmbulo) dado pelo conjunto de bits [10001011] na primeira palavra (telemetria - TLM). Na segunda palavra HOW (do Inglês "hand over word") os bits 20 - 22 são a identificação dos subquadros. A Figura 11 mostra os sub-quadros 1, 2 e 3 completos de um satélite GPS.

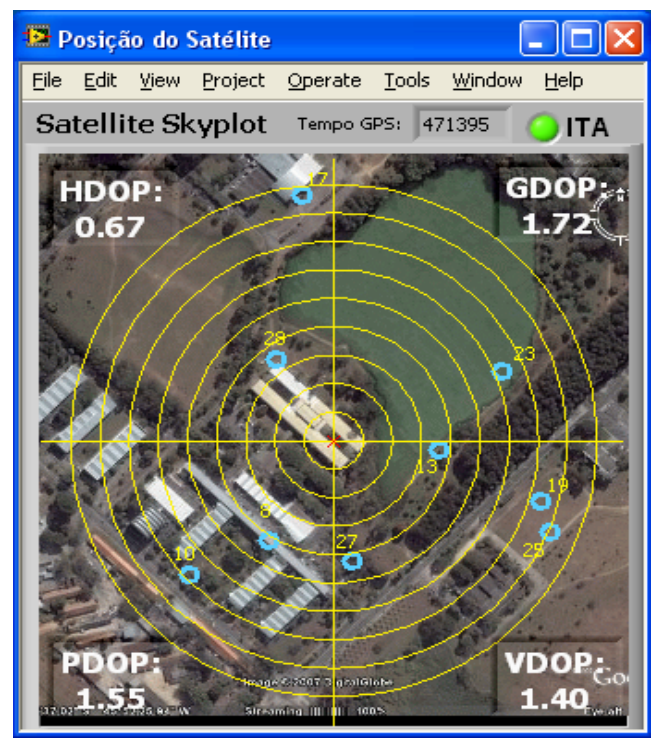

Fig. 14. Interface para visualização da posição dos satélites no Laboratório GNSS do ITA (SOW - 471395) para o dia 20 de abril de 2007. A Distribuição geométrica: HDOP ( Horizontal Dilution Of Precision) - 0,67; GDOP (Geographic DOP) - 1,72; PDOP (Position DOP) - 1,55; e o VDOP (Vertical DOP) - 1,40 são mostradas.
O GPS em software extrai os dados de navegação (efemérides) dos sub-quadros 1, 2 e 3 e calcula a posição de cada satélite. A Figura 13 mostra os dados de efemérides extraídos da mensagem de navegação apresentada anteriormente (Figura 11), outros detalhes do GPS em software para plataforma PC podem ser encontrados em [5].

\section{VI - INTERFACE DO GPS EM SOFTWARE}

As interfaces para visualização dos dados GPS foram desenvolvidas em Labview $8{ }^{\circledR}$. A Figura 14 mostra a posição dos satélites calculada utilizando-se os dados de efemérides extraídos da mensagem de navegação (sub-quadros 1, 2 e 3).

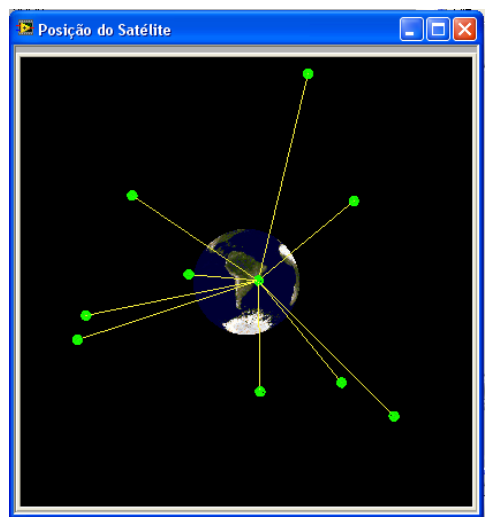

Fig. 15. Interface para visualização da posição dos satélites em formato 3D no ITA (SOW - 471395) para o dia 20 de abril de 2007.

$\mathrm{Na}$ Figura 14 o centro em vermelho corresponde ao ponto real onde se encontra a antena GPS no ITA (Latitude: 2312'34,199772', Longitude: 4552'28,503880" e Altitude: $603, .0675)$. O centro dos círculos representa o elevação de $90^{\circ}$ e cada círculo subseqüente representa uma diferença de $10^{\circ}$ na elevação $\left(80^{\circ}, 70^{\circ}, \ldots, 0^{\circ}\right)$. A Figura 15 mostra a visualização em 3D da posição dos mesmos satélites da Figura 14.

A Figura 16 mostra a posição do usuário calculada utilizando-se os 9 satélites da Figura 14.

\begin{tabular}{|c|c|c|c|c|}
\hline \multicolumn{2}{|c|}{ D. Posição do Usuário } & & & 回 \\
\hline \multicolumn{5}{|l|}{ Posiçäo: } \\
\hline \multicolumn{2}{|l|}{ Latitude: } & \multicolumn{3}{|c|}{ Tempo GPS: 105601} \\
\hline $23^{\circ}$ & $12^{\prime}$ & \multicolumn{2}{|c|}{$34.206294 \mathrm{~s}$} & \\
\hline \multicolumn{5}{|c|}{ Longitude: } \\
\hline $45^{\circ}$ & $52^{\prime}$ & \multicolumn{3}{|c|}{$28.474980 \mathrm{~W}$} \\
\hline \multicolumn{5}{|l|}{ Altitude: } \\
\hline 608.508 & 0.9 & 09 & SINGLE & \\
\hline
\end{tabular}

Fig. 16. Interface para a visualização da Latitude, Longitude e Altitude calculada pelo GPS em software.

\section{VII - Estudo dos ERros No Sistema GPS}

Com o GPS em software é possível avaliar o efeito de erros como o da troposfera e ionosfera [6]. A Figura 17 mostra o cálculo da posição do usuário quando existe a presença do efeito da troposfera e da ionosfera juntos. O CEP (Circular Error Probablility), probabilidade de erro em um círculo em torno da posição real no plano xy calculado foi de 9,6876 m em relação à posição real. O SEP (Spherical Error 
Probable), erro provável em torno de uma esfera que tem como centro a posição real (plano xyz) foi de 33,5392 m.

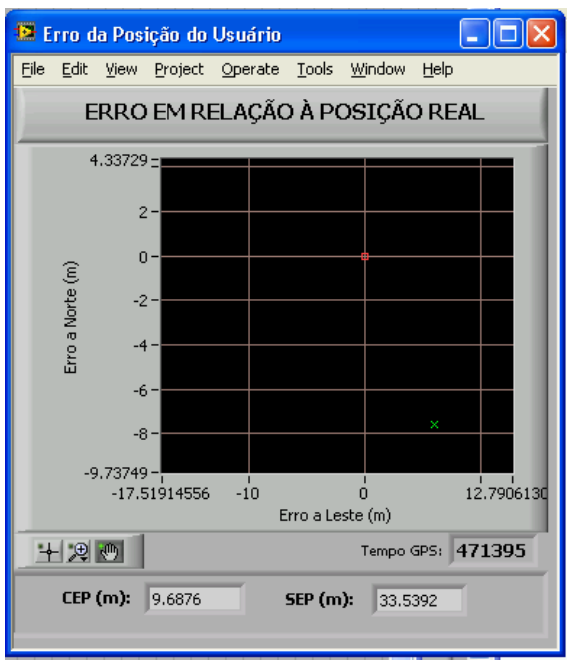

Fig. 17. Cálculo da posição do usuário sob o efeito da troposfera e da ionosfera. Ponto vermelho corresponde à posição real no ITA $(\mathrm{X}=4083783,9004, \mathrm{Y}=-4210399,3147, \mathrm{Z}=-2498296,1764)$ e о ponto verde a posição calculada. $\mathrm{CEP}=9,6 \mathrm{~m}$ e SEP $=33,5 \mathrm{~m}$.

A Figura 18 mostra o erro em X, Y e Z da posição calculada em relação à posição real quando existe a presença dos erros da troposfera e da ionosfera.

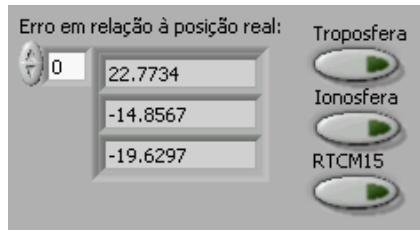

Fig. 18. Erro em X, Y e Z quando existe o efeito da troposfera e da ionosfera.

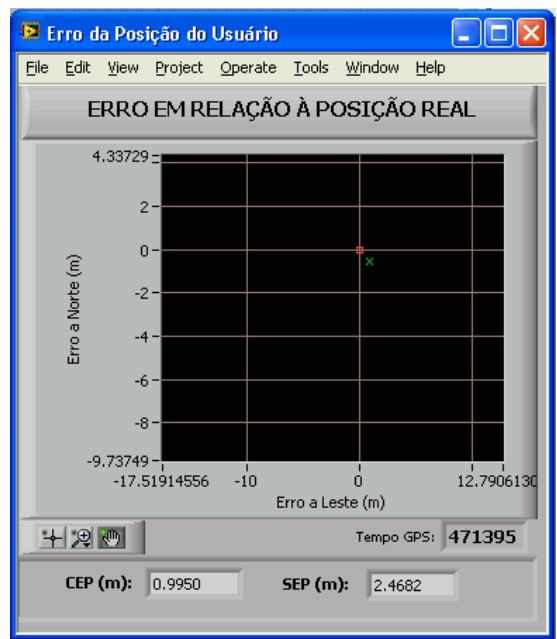

Fig. 19. Cálculo da posição do usuário sem o efeito da troposfera e da ionosfera. Ponto vermelho corresponde à posição real no ITA $(X=4083783,9004, Y=-4210399,3147, Z=-2498296,1764)$ e o ponto verde a posição calculada. $\mathrm{CEP}=0,9950 \mathrm{~m}$ e SEP $=2,4682$ $\mathrm{m}$.

A Figura 19 mostra o cálculo da posição do usuário quando os efeitos da troposfera e da ionosfera são retirados. O erro da ionosfera de cada satélite foi extraído utilizando-se a relação entre as pseudodistâncias medida em L1 e L2. O erro da troposfera de cada satélite foi calculado através do modelo de Hopfield. [7]. O CEP calculado foi de 0,995 metros em relação à posição real. O SEP foi de 2,4682 metros.

A figura 20 mostra a mesma avaliação anterior quando os erros da troposfera e da ionosfera são excluídos. Pode-se observar uma grande aproximação para as coordenadas reais $\mathrm{X}, \mathrm{Y}$ e Z.

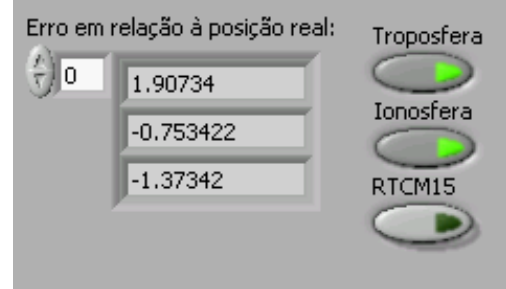

Fig. 20. Erro em $\mathrm{X}, \mathrm{Y}$ e $\mathrm{Z}$ quando não existe o efeito da troposfera e da ionosfera.

\section{VI - CONCLUÇÕES}

O receptor por software para processamento em tempo real se mostra uma ferramenta para a criação e validação de novos algoritmos de processamento, além de ter o caráter educativo, permitindo a utilização de novas técnicas para filtragem adaptativa, para redução do problema de multicaminho e erros da ionosfera e troposfera (dutos troposféricos). Esta mesma metodologia está sendo aplicada para receptores GLONASS e futuramente para o Galileo.

\section{AgradeCIMENTOS}

Este trabalho foi patrocinado por UNPD, ICAO e CTA/DECEA, através dos Projetos: "Formação de Recursos Humanos e Pesquisa para Aviação Civil", Projeto CNS/ATM, e teve o apoio da FINEP através do Projeto Pseudo-Satélite (\#01.04.0441.00) e RHODES (\#01.05. 0154.00).

\section{REFERÊNCIAS}

[1] J. B. Y. Tsui, Fundamentals of Global Positioning System Receivers, A software approach. Wiley Interscience Publicantion, 2000.

[2] F. Walter, "ET-274, Notas de Aula". Instituto Tecnológico de Aeronáutica, São José dos Campos, SP, 2003.

[3] Carvalho, F. A. e F. Walter, "Receptor GPS por Software em Tempo Real. Parte I: Geração dos Sinais", Anais do $12^{\mathrm{O}}$ Encontro de Iniciação Científica e Pós-Graduação do ITA - XII ENCITA / 2006, São José dos Campos, SP, Brasil, out., 16 a 19.

[4] Carvalho, F. A. e F. Walter, "Receptor GPS por Software em Tempo Real. Parte II: Correlator", Anais do $12^{\mathrm{O}}$ Encontro de Iniciação Científica e Pós-Graduação do ITA - XII ENCITA / 2006, São José dos Campos, SP, Brasil, out., 16 a 19.

[5] Villalba, C., L. F. e F. WALTER: Receptor GPS por Software. In: $20^{\circ}$ Simpósio Brasileiro de Telecomunicações - XX SBrT, Belém, PA, set, 2004.

[6] Oliveira, Alexandre Boa Ventura; Morais, Thiago Nunes de; Walter, Fernando. Global Behavior of Equatorial Anomaly since 1999 and Effects on GPS Signals. In: 11TH SAINT PETERSBURG INTERNATIONAL CONFERENCE ON INTEGRATED NAVIGATION SYSTEMS, 2004, Saint Petersburg, Russia, 2004.

[7] Parkinson, Bradford W.; Spilker Jr. James J., Global Positioning System: Theory and Applications- vol 1. Published by the American Institute of Aeronautics and Astronautics, Inc. Hopfield model, pp 534- 538, 1996. 